\title{
Take a peek at a clinical case of cognitive narrative therapy: the need for a new mobile narrative app!
}

\author{
Luísa Soares \\ University of Madeira \\ Campus Universitário da Penteada \\ 9000 Funchal, Portugal \\ Isoares@uma.pt
}

\begin{abstract}
This work presents a clinical case, diagnosed with anxiety - panic disorder. The client is under a process of psychotherapy, more precisely cognitive narrative therapy. It's an approach that deals with narrative writing exercises that the client has to perform at home, after the therapy sessions. We discuss how it could be quite useful having a narrative mobile app to write them down. We present here these exercises and discuss how a new app could really engage and motivate even more the therapeutic change of clients doing cognitive narrative therapy. This is an interesting way to match technology and psychotherapy. To clarify what is cognitive narrative therapy and, how an app can be of such use to the work of a narrative therapist, is the main goal of this work. Cognitive narrative therapy advocates that, the more the person is aware of his five senses, his feelings and thoughts and how he can put them into narrative words and metaphors, the more his mind is free to live mentally healthy.
\end{abstract}

Narrative therapy. App. Technology. Mental health.

\section{INTRODUCTION}

In this work we deliberatly present just one clinical case of panic attack, where cognitive narrative psychotherapy is being implemented (at the present time with 10 sessions, in an ongoing process). Throughout the intervention the use of technology and the need to create a new mobile app regarding this subject has been considered quite useful. We want to present just one clinical case, to take the opportunity to specify in particular, what is going on inside a therapeutic session, a work done only by two team workers (the therapist and his client) and how technology can come together with this team work, inside psychotherapy. Little has been done in this bridging process of connecting psychotherapy and technology. According to Coyle, Doherty, Mathews and Sharry, (2007) most attention to date has focused on electronic contact and online information sources, and electronic questionnaires for assessment, diagnosis and outcome monitoring. Computerised implementations of cognitive behavioural therapies and virtual reality based exposure therapies have also received attention, while computer gaming and multimedia storytelling have emerged more recently, demonstrating particular potential in the area of adolescent interventions (Coyle, Doherty, Mathews \& Sharry, 2007). Also the research in each of these areas is still in its early stages. Research on human computer interaction regarding psychotherapy is very poor. Engineers have no knowledge of what is happening inside a therapy session, and how can we engage technology into therapy. This work aims to show one of the techniques used in therapy, with a client with panic disorder and, how an app could really help clients and therapists to engage in some form of digital therapy.

\section{WHAT IS A PANIC DISORDER?}

Panic disorder is a type of anxiety disorder in which the person has repeated attacks of intense fear that something bad will happen. Begins suddenly, and most often peaks within 10-20 minutes. Some symptoms may continue for an hour or more. A panic attack may be mistaken for a heart attack and may include anxiety about being in a situation 
where an escape may be difficult (Stein, Goin, Pollack, Roy-Byrne, Sareen, Simon, et al, 2009). A person with panic disorder often lives in fear of another attack, and may be afraid to be alone or far from medical help. The goal of treatment is to help her to function well during everyday life. A combination of medication and cognitive-behavioral therapy (CBT) works best (Taylor, Pollack, LeBeau \& Simon, 2008). With this particular clinical case we suggest the cognitive narrative therapy developed by Gonçalves (2000), which has been working quite well with this client. He is not having medication, so cognitive narrative therapy was the best way to go.

The cost to society of mental illness is quite substantial (Coyle, Doherty, Mathews \& Sharry, 2007). Mental illness is the second leading cause of disability and premature mortality in the developed world (Murray \& Lopez, 1996). This can not be ignored by human computer interaction researchers.

\section{WHAT IS A PANIC ATTACK IN THIS STYLE OF CLIENT?}

$\mathrm{He}$ is a 40 years old man with a very reflexive style of thinking. He is very prone to use technology and to write. Also he is professionally linked to the fields of literature and communication. He has been showing a good aptitude to receive this kind of cognitive narrative treatment. He has some difficult identifying emotions and describing some hurtful events of his life, taking into consideration the use of the 5 senses. These are the narrative dimensions more hard for him to work on. We are half way on the treatment process and, in one of the sessions, he came across the idea of, imagine an app which could guide him on his narrative exercises, and help him improve the writing of those dimensions (5 senses and emotions). Our main goal is to help him decentralize from the panic thoughts and symptoms and become more aware of what is around him using his vision, smell, hearing, taste and kinesthetic sensations in his body. In the meantime, it is also important to be ware of his thoughts and feelings in order to be open to new positive meanings of that hurtful experience.

His panic attacks are less frequent for now, but the fear of something could happen in the future is sometimes overwhelming for him. He describes a panic attack as having trouble breathing, a pain in the heart, a thought that he is going to die. Sometimes he also feels a pain in the stomach. This fear and thoughts blocks him from leading a relaxed daily life.

Every now and then, he describes some symptoms of depression, like amotivation to work, to do some physical activity, stays home a lot. Sometimes this disorder, if not treated, can develop to a major depression.

$\mathrm{He}$ is also a very cautious person with his food. He takes care of eating quite healthy food, but when that does not happen, which is rarely, the thoughts of having a disease or dying are quite over proportional and the panic attacks occurs.

\section{WHAT IS COGNITIVE NARRATIVE THERAPY?}

Cognitive Narrative Therapy is an updated version of cognitive therapy. It's an approach that takes into consideration four dimensions in therapy: a) the use of our five senses (hearing, smell, taste, vision and touch), when describing episodes of our daily live; b) the description of our feelings on those episodes; c) the description of our thoughts and, d) the use of metaphors to give meaning to our experiences. Figure 1 shows more clearly the dimensions of narrative therapy. The more diverse, enriched and coherent are one person's narrative, the more she can deal with adverse experience of the daily live. Cognitive narrative therapy tries to stimulate the work with the client on putting in practice, that is to say, in word writing and verbally, these four dimensions. The work is done in each session and with each daily episode chosen by him. Also, the client has to do them at home, one per day. Through therapeutic conversations about hurtful parts of their lives, new meanings could be shaped and new life options can become available. Live trough narrative, implies to describe the troubles in our lives and, by doing that, create new meanings (Bruner 1990; Gonçalves, 2000). Narrative therapy is based on the notion that we generate stories in an effort to make sense of our lives. One of the features that distinguish us while human beings, is our ability to use language in the construction of our personnel experiences (Gonçalves, Henriques \& Machado, 2004).

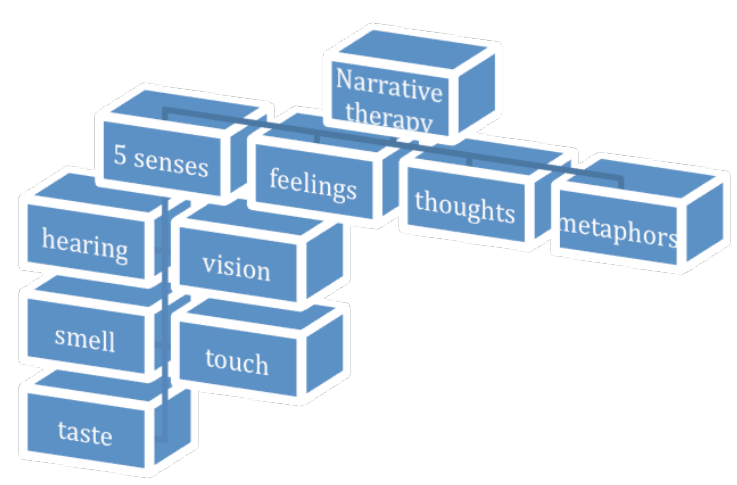


Figure 1: Dimensions of narrative therapy approach

In Cognitive Narrative Therapy we work in a synchronic and diachronic way. It is asked the client to identify one significant episode for each year of his life and, he also writes one significant episode that occurred in each day. Then, they need to be enriched with narrative ingredients: "what are you smelling, hearing, tasting, visualizing and kinesthetic sensations in the body"; "what thoughts come trough your mind"; "what are you feeling describing all that" and "what metaphor best describes this episode". This opens up to new meanings and distracts the client from the hurtful episode. It also opens up to the diversity of things that are occurring at the same time he is feeling pain and that, could help diminish that pain.

\section{THE NEED FOR A MOBILE COGNITIVE NARRATIVE APP}

A mobile cognitive narrative app could be designed taking into account the questions presented above, regarding "what are you smelling, hearing, tasting, visualizing and kinesthetic sensations in the body"; "what thoughts come trough your mind"; "what are you feeling describing all that" and "what metaphor best describes this episode". Moreover, the app could highlight when the person is doing quite well in the description of the episode, that is to say, the more diverse in terms of the use of the 5 senses, the more clearly identified thoughts and feelings, the more coherent and opened up to new positive meanings, the higher the level of narrative productivity. This could really work quite well with those clients more prone to use technology and writing. They could feel daily reinforced if they have a daily feedback on what are their levels of narrative therapeutic productivity. I guess we could call them, in the future, digital clients in therapy that produce digital experiences of their daily life. Technology helps to engage in a more creative dimension and that works also as a motivator. Everyone has a mobile phone nowadays and more important, they spent a lot of the daily time looking at it and checking messages. Let's use that attractiveness towards mobile phone and put it into a therapeutic use.

The main idea is to create an app that detects if the person is using all the narrative dimensions and the results could show in graphic mode.

In cognitive narrative therapy, when the person manages to unblock painful moments, and starts to pay attention to pleasant moments that always occur in our lives, they are on the right track. Sometimes we are just blocked by psychological disorders. The clue is to acknowlodge the good and the bad moments in life, talk about it, integrate them in our mental computer and MOVE ON to new and future narrative experiences. Technologies for engagement in psychotherapy have received less attention and a lot has to be done by therapists, to show other professionals, how to design such technologies. As Coyle, Doherty, Mathews and Sharry, (2007) pointed out, engagement is critical to building client-therapist relationships and improving client self- efficacy. Moreover, design guidelines should also be pointed out to therapists for creating usable and captivating interfaces.

\section{REFERENCES}

Bruner, J. (1990) Actos de Significado. V. Prazeres Trad. Lisboa: Edições 70.

Coyle, D., Doherty, G., Sharry, J. \& Matthews, M. (2007). Computers in Talk-based mental health interventions, Interacting with Computers, 19(4), pp.545-562.

Gonçalves, O. (2000). Viver narrativamente. A psicoterapia como adjectivação da experiência. Coimbra: Quarteto editora.

Gonçalves, O., Henriques, M., Machado, P. (2004). Nurturing Nature. Cognitive Narrative Strategies. In Lynne E. Angus \& John MacLeod (Eds), The Handbook of Narrative and Psychotherapy. (pp. 103-118). Sage Publications.

Murray, C. L., \& Lopez, A. D. (Eds.). (1996). The Global Burden of Disease: A comprehensive assessment of mortality and disability from disease, injuries, and risk factors in 1990 and projected to 2020. Cambridge, MA: Harvard University.

Stein, M. B., Goin, M. K., Pollack M. H., Roy-Byrne P., Sareen J., Simon N. M., et al. (2009). Practice guideline for the treatment of patients with panic disorder. Arlington, VA: American Psychiatric Association.

Taylor, C. T., Pollack M. H., LeBeau R.T., Simon, N. M. (2008). Anxiety disorders: Panic, social anxiety, and generalized anxiety. In Stern T. A., Rosenbaum J. F., Fava, M., Biederman J., Rauch S. L., (eds). Massachusetts General Hospital Comprehensive Clinical Psychiatry. 1st ed. Philadelphia, Pa: Mosby Elsevier; chap. 32. 